\title{
織物の反射光分布曲線のシミュレーション
}

（第 1 報）楕円柱面上に小円筒を配列したモデルによる反射光分布曲線の計算

\begin{tabular}{|c|c|c|c|c|c|}
\hline 東海大学 & 工学部 & 武 & 藤 & 信 & 男* (会員) \\
\hline 明治大学 & 工学部 & 荒 & 井 & 俊 & 彦** (" ) \\
\hline " & & 仁 & 平 & 幸 & 治** (") \\
\hline 愛知工業大学 & 工学部 & 坪 & 井 & 常 & 世***(" ) \\
\hline 妻女子大学 & 家政学部 & 軍 & 司 & 每- & 博****(") \\
\hline
\end{tabular}

\section{Computer Simulation on Goniophotometric Curves of Fabrics.}

Part 1: The Fabric Model Made of Elliptic Column Yarns

Covered with Fine Cylinders.

\author{
Nobuo Muto*, Toshihiko Arai**, Koji Nihira**, Tsuneyo Tsuboi*** \\ and Toshihiro Gunji****, \\ *Faculty of Engineering, Tokai University, Kanagawa. \\ ${ }^{*}$ Faculty of Engineering, Meiji University, Kanagawa. \\ ***Faculty of Engineering, Aichi Institute of Technology, Aichi. \\ ****Faculty of Home Economics, Otsuma Women's University, Tokyo.
}

\begin{abstract}
Authors have previously reported that the distribution curve of a specular reflection light, i.e., goniophotometric curve, on fabrics can be calculated by using the simple cross-sectional elliptic model. The experimental results agreed well with these calculated curves. It is necessary, however, to assume a model more similar to fabrics, because the surface of fabrics is much complicated.

The goniophotometric curves were obtained by a computer simulation by using a new model, in which a parallel luminous flux was assumed to be applied to the fabrics. The new model is so assumed that fine cylinders are arranged side by side on the surface of an ellipsoid. In this computer simulation, the axis of incident flux and photodetector were assumed to be perpendicular to the filaments of fabric, and the reflection light was calculated from the view point of luminous intensity.

The method of the calculation is more applicable than that of the previous paper. (Received December 10, 1981)

\section{摘 要}

目的 前報において織物の正反射光分布曲線を計算より求めるために，単純な楕円柱面モデルを用いて織物の表面よりの正反射 光分布曲線を計算し，その傾向が測定結果と似ていることを報告した.

しかしながら，実際の織物の表面は複雑であるのでそれに対応してモデルをより近似度の高いものにすることが必要である. そ のためにはモデルの条件を変えて計算を行う必要がある. 今回は織物の上層の織維に対して入射平行光束の光軸と受光軸とが緘維 に対して垂直になるような場合を考えて，楕円柱面上に小円筒を規則的に配列したモデルを基本モデルとし，正反射光分布曲線に ついてコンピュータ シミュレーションを行った.
\end{abstract}

成果 前報の結果に対して反射光光度としての取扱いを厳密に行い, かつ各種条件を変えた精度の高い計算を行った.

(昭和56年12月10日受理) 


\section{1. まえがき}

前報1)(2)において, 織物表面のモデルとして極めて単 純化した棈円柱面モデルと，楕円柱面上に規則的に配列 した円筒のモデルを使って, 織物の正反射光分布曲線を 近似的に計算した。 そして計算結果の傾向が, 測定結果 の傾向と良く似ていることを確認した.

しかしながら, 実際の織物の表面の正反射光分布曲線 を計算によって求めることは織物の表面が複雑であるの で, それに対応してょり近似度の高いモデルにすること が必要である. したがって, このような織物の表面の反 射光分布曲線を求めるために, モデルによるコンピュー タ シミュレーションを行う必要がある. しかもこれに 関する報文はあまり多くない。

そこで, 筆者等は電子計算機を使用し, モデルの条件 をいろいろと変えてコンピュータ シミュレーションを 行った。

一般に織物に平行光束が入射した場合測光面を,たて 系の軸に垂直になるようにすれば，よこ系には平行とな る. したがって, たて方向, よこ方向, それぞれの正反 射光成分を考える場合は瀻維の配列に対して, 測光面が 垂直な場合と平行な場合の組合せとして考えればよい. この 2 つの正反射光成分に層内拡散反射成分が重ね合せ られたものが, 反射光分布曲線となる.

今回は, 織物の上層の繊維の配列に対して入射平行光 束の光軸が緘維軸に垂直になるような場合について正反 射光分布曲線をモデルを使ってコンピュータ シミュ レーションを行った。その条件を満たすモデルとして, 楕円柱面上に小円筒を規則的に配列したモデルを基本モ デルとして，正反射光分布曲線を計算した．さらに前報 の結果に対した反射光光度としての取扱いを厳密に し，かつ精度の高い計算が得られるようにコンピュータ シミュレーションを行った.

\section{2.モデルと基本計算}

実際の織物では繊維の束の断面はほぼ棈円状になって いて, その最上層の部分はおよそ十数本の単繊維が存在 するとみなした．また，その単繊維の断面形状は各種の 形が考えられるが，今回の計算では図 1 のような棈円柱 面上に小円筒を配列したモデルを使用した。

楕円柱面は長径を 2 , 短径を $2 k$, 軸方向の長さを 1 として, 中心軸を通る平面によって隣りのものと連結さ れ，しかも連結部分は反射光分布曲線にはまったく影響 がないものとして無視した．棈円柱面上の小円筒は実際 の織物の最上層の単繊維に対応するもので, 柱面の断面 上に中心をもつ半径 $r$ の小円筒で, 10～20個ほど,すき まなく並べられているものとした。

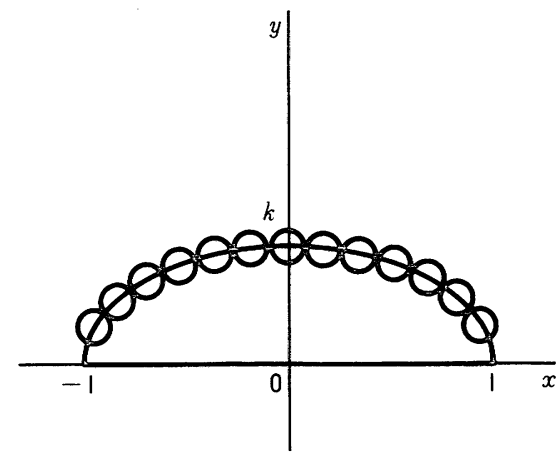

図 1 棈円柱面上に小円筒を規則的に配列したモデル

測光面が楕円柱の中心軸に垂直で, 測光中心が中心軸 上にあり,楕円柱の軸方向に単位長さを取っているので, 二次元としての取扱いが可能となる.この楕円柱面に入 射角 $\varphi$ で平行光束を投射した時の正反射光分布曲線を計 算した。

いま図 2 のような棈円上点の $O_{n}\left(x_{n}, y_{n}\right)$ に中心を もつ半径 $r$ 小小について考える.

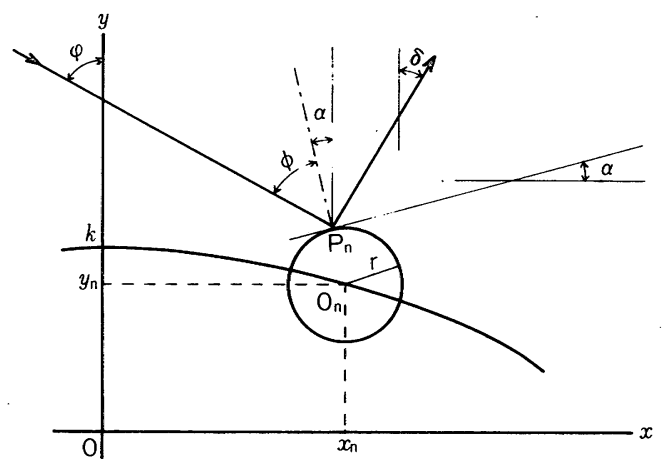

図 2 楕円面上の小円筒の光学的関係

入射光束は平行光束であるので, 入射光をシミュレー トした方程式は,

$$
y=x \tan \left(\frac{\pi}{2}+\varphi\right)+c
$$

と表わすことができる．ただし $c$ は切片である.

また小円の方程式は

$\left(x-x_{n}\right)^{2}+\left(y-y_{n}\right)^{2}=r^{2}$ となる.

(1)式で表される入射光が(2)式で表される円と交差すれ ば反射点が存在し正反射光が生ずる.

(1)式を(2)式に代入して

$$
\begin{aligned}
& x^{2}\left\{1+\tan ^{2}\left(\frac{\pi}{2}+\varphi\right)\right\}+2 x\left\{\left(c-y_{n}\right)\right. \\
& \left.\tan \left(\frac{\pi}{2}+\varphi\right)-x_{n}\right\}+\left\{x_{n}^{2}+\left(c-y_{n}\right)^{2}-r^{2}\right\}=0
\end{aligned}
$$




$$
\begin{aligned}
& A=1+\tan ^{2}\left(\frac{\pi}{2}+\varphi\right) \\
& B=2\left\{\left(c-y_{n}\right) \tan \left(\frac{\pi}{2}+\varphi\right)-x_{n}\right\} \\
& C=x_{n}^{2}+\left(c-y_{n}\right)^{2}-r^{2}
\end{aligned}
$$

とすれば，(3)式の判別式は

$$
D=B^{2}-4 A C
$$

となる。

ここで， $D>0$ の場合入射光は円 $O_{n}$ に当たり反射点 が存在する. (3)式の解を $x_{a}, x_{b}$ とすれば,

$$
x_{a}=\frac{-B+\sqrt{D}}{2 A}, \quad x_{b}=\frac{-B-\sqrt{D}}{2 A}
$$

$x_{a} \geqq x_{b}$ なるとき反射点 $P_{n m}$ の $x$ 座標 $x_{n m}$ は

$$
x_{n m}=x_{0}
$$

となる.またその $y$ 座標 $y_{n m}$ は(1)式より

$$
y_{n m}=x_{n m} \tan \left(\frac{\pi}{2}+\varphi\right)+c
$$

となる。

したがって, 点 $P_{n m}$ における反射光の受光角を $\delta$ と すれば反射光の方程式は

$$
y=x \tan \left(\frac{\pi}{2}-\delta\right)+y_{n m}-x_{n m} \tan \left(\frac{\pi}{2}-\delta\right)
$$

となる。

円 $O_{n}$ の反射点 $P_{n m}\left(x_{n m}, y_{n m}\right)$ における接線の勾配 は

$$
\tan \alpha=\frac{x_{n}-x_{m m}}{\sqrt{r^{2}-\left(x_{m m}-x_{n}\right)^{2}}}
$$

となる.したがって点 $P_{n m}$ における法線の傾き角 $\alpha$ は,

$$
\alpha=\tan ^{-1} \frac{x_{n}-x_{n m}}{\sqrt{r^{2}-\left(x_{n m}-x_{n}\right)^{2}}}
$$

となる。

なお点 $P_{n m}$ の受光角 $\delta$, またその微少素面の入射角 фはそれぞれ

$$
\begin{aligned}
& \delta=\varphi-2 \alpha \\
& \phi=\frac{\varphi+\delta}{2}
\end{aligned}
$$

となる。

次に図 3 において，入射平行光束を等分割してそれぞ れの反射点を $P_{n m}, P_{n m+1}, P_{n m+2}$ とすると, それぞれ の反射角は $\delta n m, \delta_{n m+1}, \delta_{n m+2}$, となる. したがって, その $P_{n m}, P_{n m+1}$ の反射光の立体角を $d \omega_{n m}$ とすれば, 中心軸上の長さは 1 であるので

$d \omega_{n m}=\delta_{n n+1}-\delta_{n m}$

となる.

反射光分布曲線は光度を測定しているので，各反射光 の光度 $d I$ は,

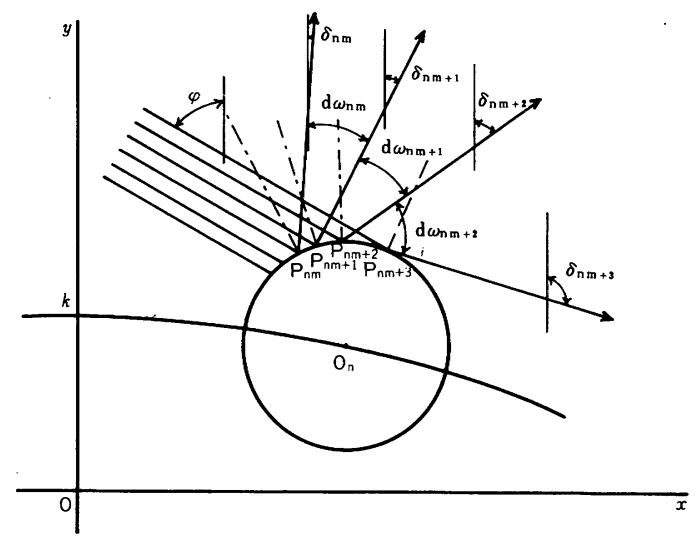

図 3 立体角の説明図

$$
d I=\frac{d F}{d \omega}
$$

$d F ， d \omega$ はそれぞれ入射平行光束，立体角である.

$d F$ は一定であるので，それを 1 と仮定すると，試料 の屈折率 $n$ 亡微小素面の入射角 $\phi$ により決まるフレネ ル係数を $f(\phi, n)$ とすれば, 点 $P_{n m}$ の正反射光光度 $\Delta I(\delta)$ は

$$
\Delta I(\delta)=f(\phi, n) \cdot \frac{1}{d \omega} \cdot \cos \phi
$$

となる.

この考え方に従ってすべての小円について, 受光角 $\delta$ の正反射光光度 $\Delta I(\delta)$ を求める.

このようにして各反射点における正反射光強度が求め られるが，その各反射光軸は測光中心である $O$ 点に結 ばず，受光条件は完全ではない．しかしながら楕円柱面 の径が測定系の径と比較して無視し得るほど小さいの で，各反射光軸は測定中心 $O$ に集まるものと仮定して 計算しても差し支えない.

次にこの反射光が隣接小円柱で遮られて二次反射光に なる場合，さらに隣接楕円柱面に遮られて二次正反射光 になる場合の両者については極めて小さいのでこれを零 と仮定して計算を行う．したがって，その2つの場合に ついてそれぞれ正反射光が遮られるか, 否かの判定を行 う。

図 4 において, 円 $O_{n+1}$ の方程式は

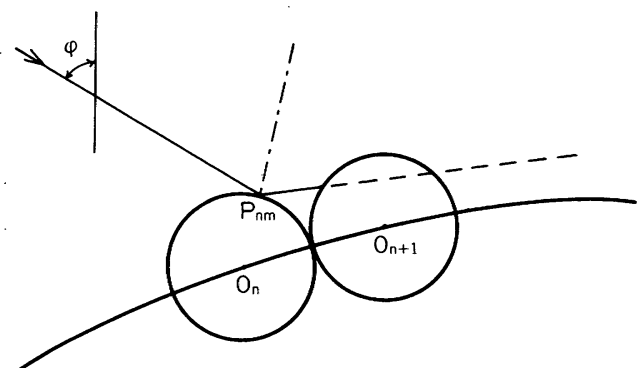

困 4 反射光と隣接小円との関係 
$\left(x-x_{n+1}\right)^{2}+\left(y-y_{n+1}\right)^{2}=r^{2}$

である. (8)式を(16)式に代入して

$$
\begin{aligned}
& x^{2}\left\{1+\tan ^{2}\left(\frac{\pi}{2}-\delta\right)\right\}+2 x\left[\tan \left(\frac{\pi}{2}-\delta\right)\right. \\
& \left.\quad\left\{y_{n m}-x_{n m} \tan \left(\frac{\pi}{2}-\delta\right)-y_{n+1}\right\}-x_{n+1}\right] \\
& +\left[\left\{y_{n m}-x_{n m} \tan \left(\frac{\pi}{2}-\delta\right)-y_{n+1}\right\}^{2}\right. \\
& \left.+x_{n+1}^{2}-r^{2}\right]=0
\end{aligned}
$$

ここで(17)式の判別式を $D_{1}$ とすれば， $D_{1}>0$ の時反射 光は隣接小円柱で遮られる.

同様に(8)式で示される反射光が隣の楕円に当たるかど うかの判定を行う.

図 5 の楕円 II において，楕円上に小円筒が存在する凹

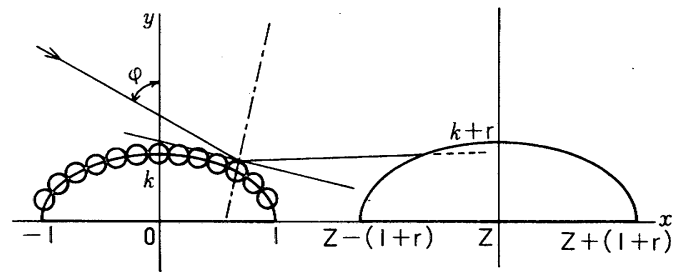

図 5 反射光と隣接棈円との関係

凸のある表面を表面がなめらかな楕円柱面で近似する と, その断面の方程式は,

$$
\frac{(x-z)^{2}}{(1+r)^{2}}+\frac{y^{2}}{(k+r)^{2}}=1
$$

となる（8)式を(18)式に代入して

$$
\begin{aligned}
& x^{2}\left\{(k+r)^{2}+(1+r)^{2} \tan ^{2}\left(\frac{\pi}{2}-\delta\right)\right\}+ \\
& 2 x\left[(1+r)^{2} \tan \left(\frac{\pi}{2}-\delta\right)\left\{y_{n m}-x_{n m} \tan \left(\frac{\pi}{2}-\delta\right)\right\}\right. \\
& \left.-(k+r)^{2} z\right]+(1+r)^{2}\left\{y_{n m}-\right. \\
& \left.x_{n m} \tan \left(\frac{\pi}{2}-\delta\right)\right\}^{2}+(k+r)^{2} z^{2}- \\
& (k+r)^{2}\left(1+r^{2}\right)=0
\end{aligned}
$$

ここで判別式を $D_{2}$ とすれば， $D_{2}>0$ の時反射光は隣接 楕円柱面に遮られる.

以上 $2 つ$ 判定で反射光が零となれば(15)式の正反射光 光度 $\Delta I(\delta)$ は

$$
\Delta I(\delta)=0
$$

となる。

このようにして一個の小円についての正反射光光度が 求められるが，これを楕円柱面上すべての小円について 求め, 同一受光角について加えれば，正反射光分布曲線 が求められる.

\section{3.コンピュータによるシミュレーション}

図6(a)は実際の計算で用いたフローチャートである. また図 6(b)〜図 6(h) はそれぞれ, 座標, 反射光強度, 判 別式, 立体角, 反射点, 印刷のサブルーチンを示した ものである.

図 7 は図 6 のフローチャートに従ってコンピュータ シミュレーションを行った一例で, 屈折率 $n=1.5$, 入 射角 $\varphi=45^{\circ}$, 楕円の短径について $k=0.25$, 円筒の半

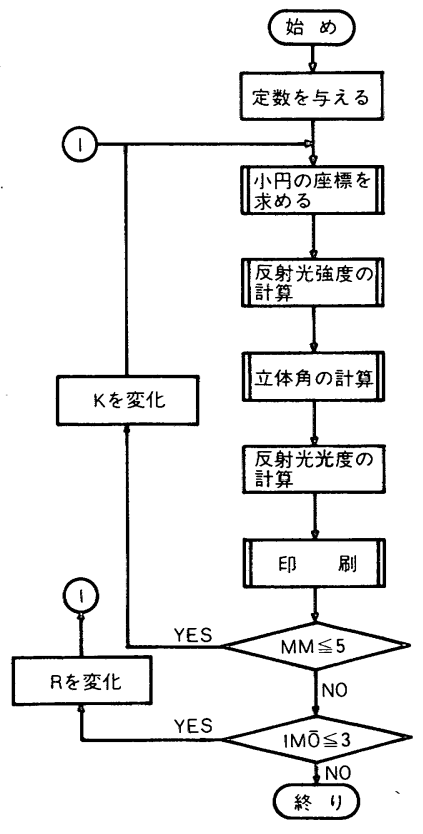

図6(a) メインフローチャート

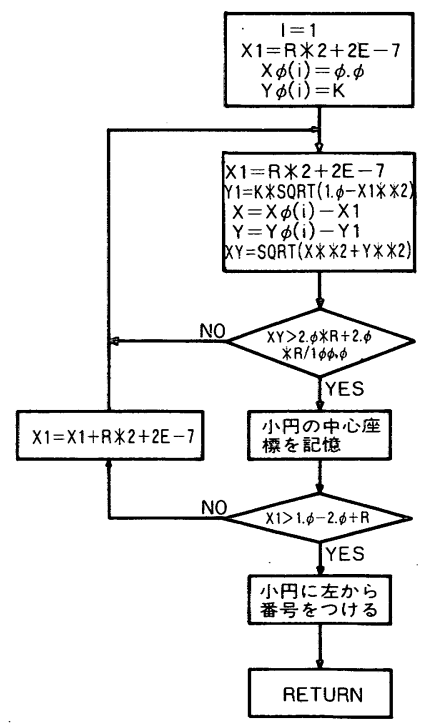

図6(b) 座標を求めるサブ ルーチン 


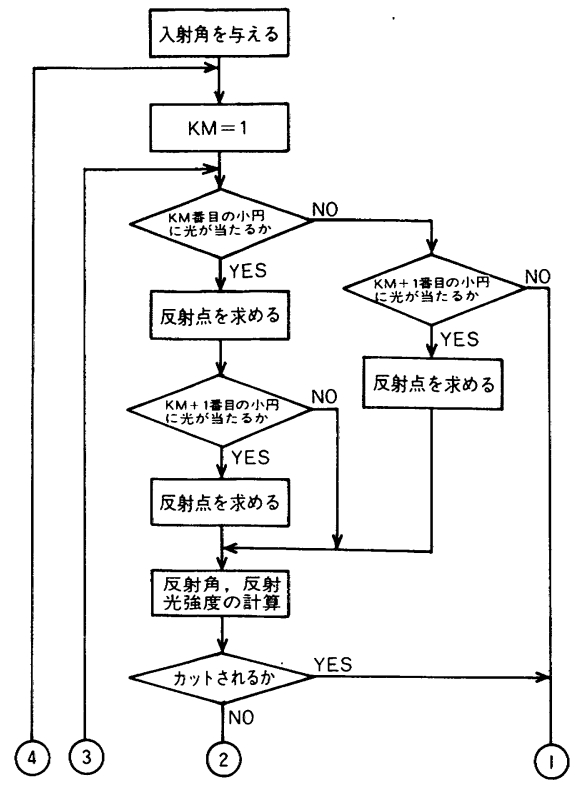

図 6(c) 反射光強度を求めるサブ ルーチン (1)

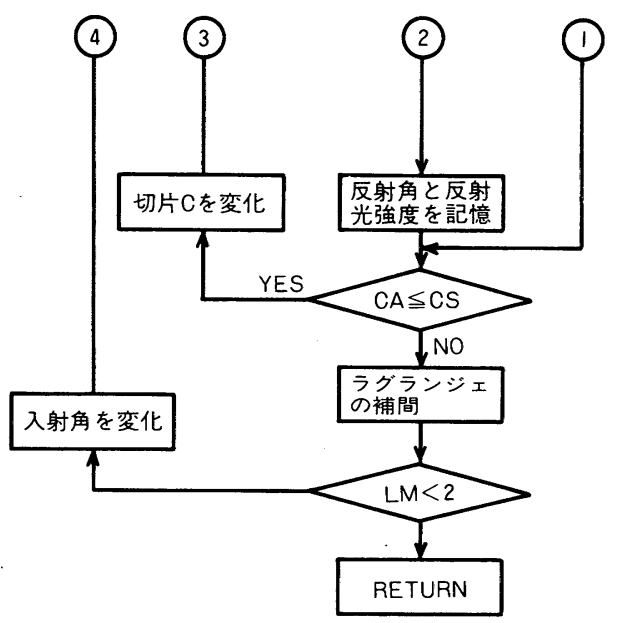

目 6(d) 反射光強度を求めるサブ ルーチン（2）

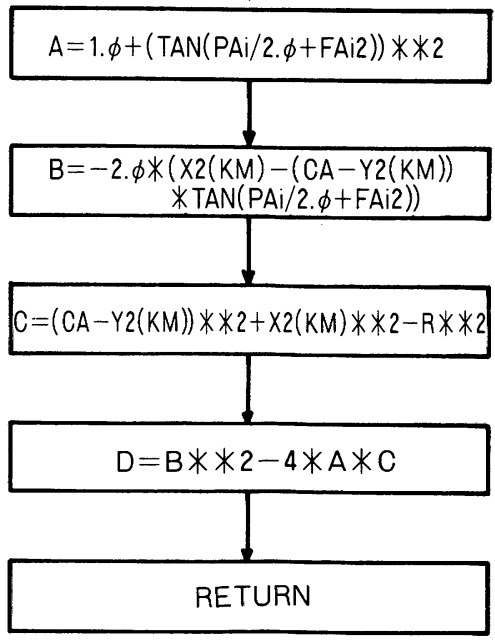

図 6(e) 判別式のサブ ルーチン

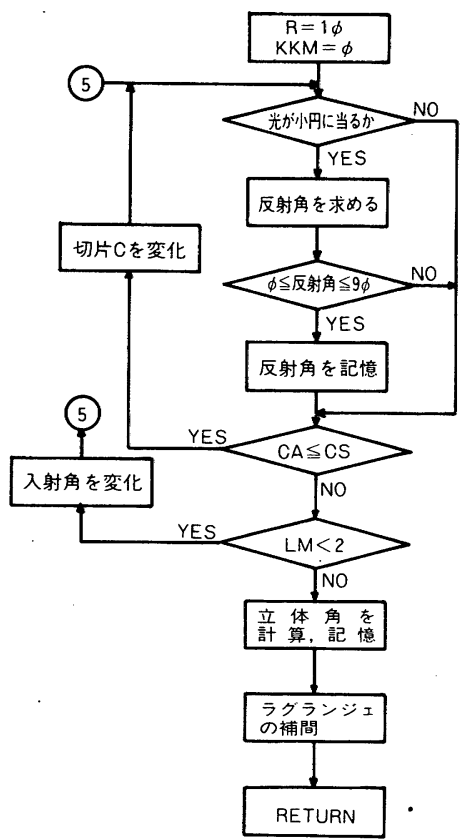

図6(f) 立体角を求めるサブ ルーチン

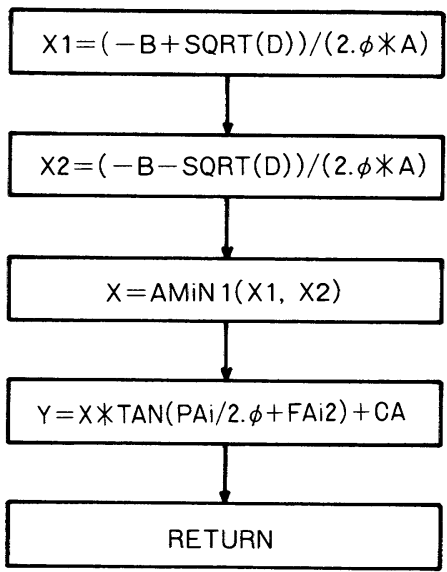

図 6(g) 反射点を求めるサブ ルーチン
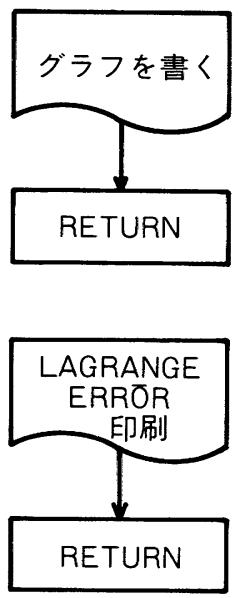

図 6(h) 印刷のサブ ルーチン 


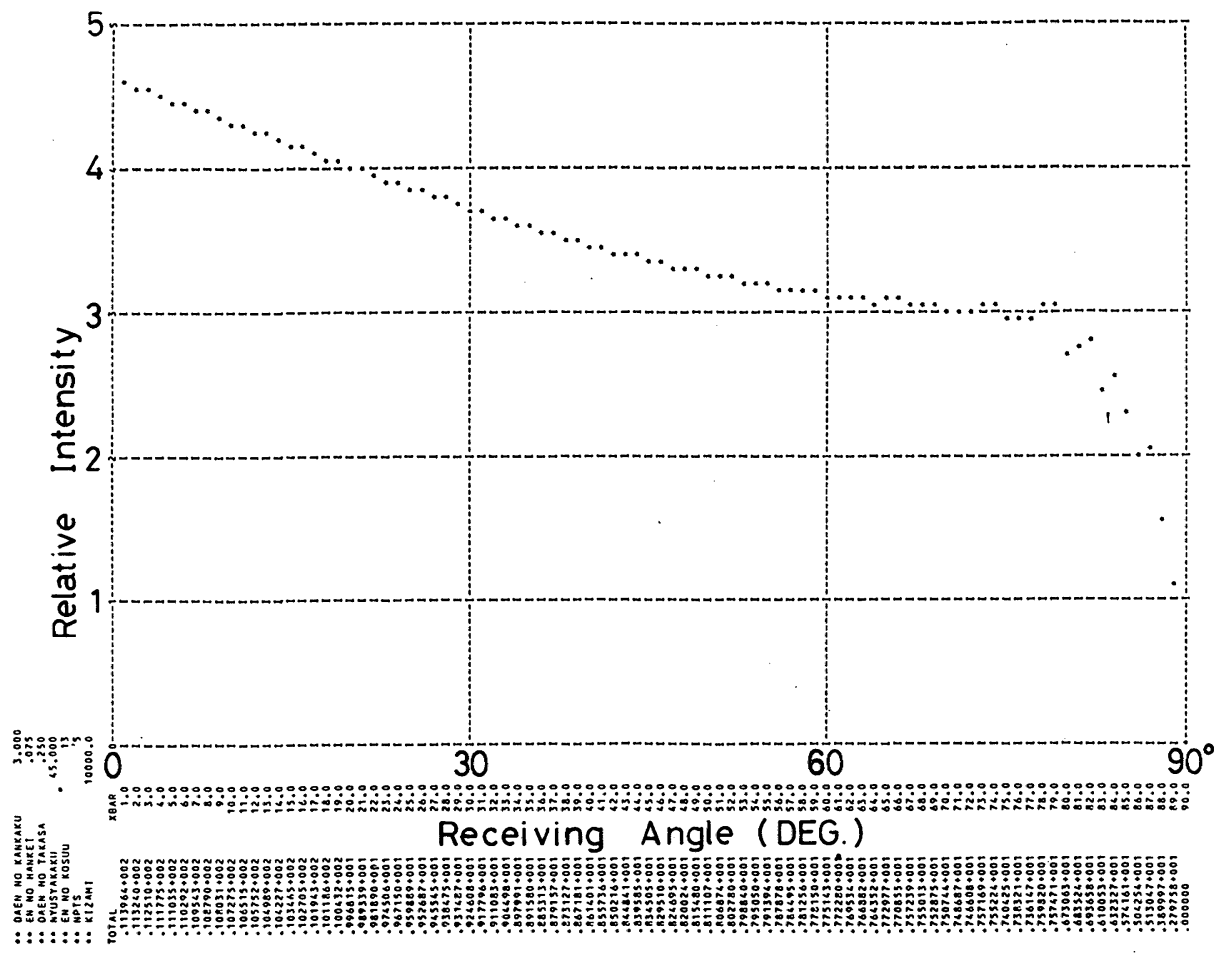

図７コンピュータ シミュレーションの一例

径 $r=0.075$ (円筒の個数=13）とした場合の受光角に 対する正反射光分布曲線の印刷結果である。本報文の計 算例においては, すべて屈折率 $n=1.5$ として計算して ある。

\section{4. シミュレーションの結果と検討}

図 8 , 図 9 は棈円の短径について $k=0.5$ とし, 小円 の半径 $r$ をパラメータとしたときの入射角 $\varphi$ をそれぞれ $45^{\circ}$ と $60^{\circ}$ としたときの正反射光分布曲線の計算結果で ある. 入射角 $\varphi$ が $45^{\circ}$ のとき小円の半径 $r$ の值が小さく なると, 正反射光光度は同じ形で大きくなる. 入射角 $\varphi$

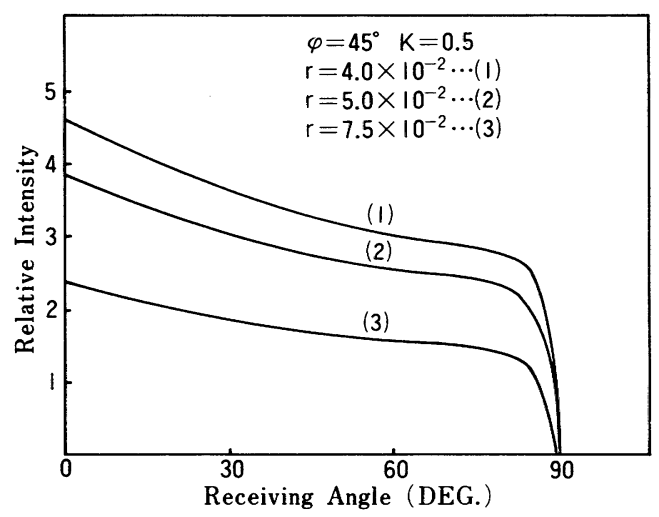

困 8 入射角 $45^{\circ}$ の正反射光分布曲線の計算結果

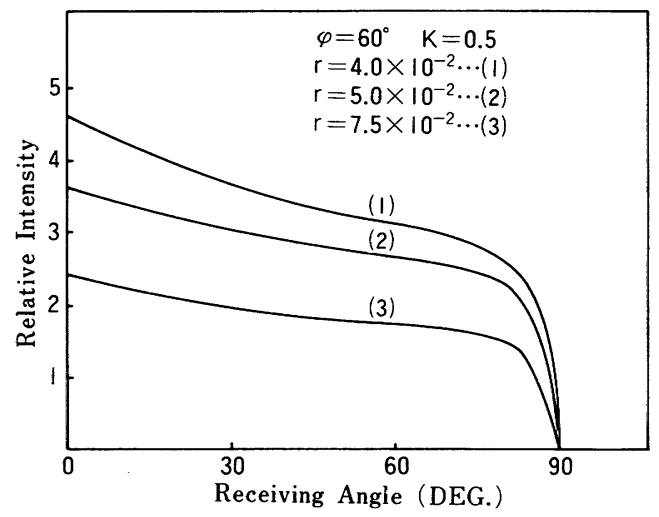

図 9 入射角 $60^{\circ}$ の正反射光分布曲線の計算結果

が $60^{\circ}$ の場合も同様である. なお入射角 $\varphi=45^{\circ}, 60^{\circ}$ の とき $k$ を変えても正反射光分布曲線はほとんど変化し ない.

小円の半径 $r$ の值が小さくなると正反射光光度が増加 するのは, $r$ の值が小さくなるに従って, 楕円上の小円 の個数が増加し，その結果正反射に寄与する微小素面の 数が増加してくるためと考えられる.

今回の計算では織物の上層の繊維に対して入射平行光 束の光軸と受光軸が繊維軸に対して垂直になるような場 合についてのみ行った. そのため, 測定結果と直接比較 することは不可能である．また上層緎維のモデルとして 
断面が円形のものを考えた. 実際の織物の繊維は, この ような単純なものではなく，断面が楕円形など円形と異 なった形状を持っているので次回以降においてはこれを 考慮し種々の条件を変えシミュレーションを行う.さら に他の 2 成分についてのシミュレーションを併せて行 い, 3 成分の重ね合せとして, 測定結果と比較検討が可 能となる.

\section{5.あとがき}

今回は織物の上層の繊維に対して入射平行光束の光軸 と受光軸が繊維軸に対して垂直になるような場合につい ての正反射光分布曲線のコンピュータ シミュレーショ
ンを行った。そのモデルとして楕円柱面上に円筒を敷き 並べたものを考えて計算した。しかし実際の織物の繊維 はその断面形状として各種のものが用いられている. し たがって今後その断面形状を例えば多角形, 棈円形等に ついて行えば, 実際の織物面の反射光分布曲線に近いシ。 ミュレーションが得られるものと考えられる.このよう にして, 近似度の高いシミュレーションが得られれば, 織物面の光沢の量的, 質的評価の解析に役立つものと考 え研究を進めている.

\section{参考文献}

1）仁平, 坪井, 軍司; 瀻機誌, 30, T 23 (1977)

2) 仁平, 坪井, 軍司; 織機誌, 30, T 77 (1977) 